\title{
Hacia una poética de la obsesión en Borges: formas e identidades rizomáticas
}

\author{
D Avid F. RichteR*
}

'Borges' central obsession is Borges. ${ }^{1}$

Willis Barnstone

El pensamiento sin imagen deleuziano no negocia con invariantes, certezas, religiones, sino que se vincula a los procesos, a las diferencias, a las multiplicidades, a las variaciones, promoviendo la relación estrecha entre el pensamiento y el devenir, 0 aún más, transformando el propio pensamiento en un devenir, es decir, en una potencia creativa, en una máquina productiva.

Alberto Casabona

Resumen:

En el trabajo presente se examina la poesía tardía del escritor argentino Jorge Luis Borges y la manera en que la obsesión con la identidad se manifiesta no solamente como un tema principal, sino también la manera en que esta obsesión se desdobla en preocupaciones tanto temporales como formales. A la vez, la obsesión con la identidad y el interés en cómo se constituye el yo afirma una identidad no estable y un yo que está en flujo continuo; lo que Deleuze y Guattari llaman una producción nómada

* Vanderbilt University.

${ }^{1}$ [La obsesión central de Borges es Borges mismo (136)]. Las traducciones de éstay demás citas son mías, excepto aquellos casos en que se indicala referencia de su edición en español. 
y rizomática. El estudio de estas obsesiones de identidades y formas rizomáticas ofrece una nueva mirada hacia la poética borgeana como una metapoética de fugas. Al analizar la poesía de Borges dentro de tal esquema esquizoanalítico se puede comprobar y destacar las preocupaciones de identidad y cómo el desarrollo de tales obsesiones constituye la esencia indefinible y fugaz de la poética borgeana.

Palabras clave:

Jorge Luis Borges, literatura argentina, D eleuzey G uattari, rizoma.

\section{Una poética indefinible}

D efinir o delimitar una poética de Borges resulta sumamente problemático. Es decir, precisar unas limitaciones en la obra borgeana va directamente en contra de lo que Borges proclama lograr con sus obras. Él mismo resiste las restricciones o la clausura de su obra poética que las definiciones fijas pueden causar. Es probablemente por eso que existen tantas lecturas de Borges o tantos acercamientos teóricos y críticos a sus obras. Cada crítico quiere resolver a Borges, poner unas limitaciones y así poder explicarlo y razonarlo dentro de ciertos parámetros críticos, filosóficos o históricos. De aquí saltan un par de preguntas que merecen cierta atención: ipor qué resiste la fijación la poética de Borges? Y si no podemos definir esta poética, ¿Cómo se puede por lo menos aproximar una explicación de ella? Lo que sostengo aquí, y lo que me interesa poner a prueba, es que la poética borgeana sí se puede definir, pero sólo como un fenómeno indefinible y en constante flujo.

A la vez se debe reconocer que parte del problema reside en que el enfoque crítico generalmente se basa en la obra narrativa del escritor argentino. Antes que nada hemos de establecer la importancia de la obra poética de Borges en su trayectoria literaria y al dejar claro eso, ya podremos entrar en los problemas de las obsesiones, las identidades múltiples y las poéticas de fuga. Al ver la importancia del estudio de la obra poética de Borges, se podrá captar 
mejor que las obsesiones de Borges coinciden con su estilo poético y con la imposibilidad de definirlo. Es decir que la obsesión por una interrogación del yo, la cual alude a una serie de yos múltiples y rizomáticos, se desdobla en una poética de flujos y fugas tanto temáticos como formales que resisten delimitaciones.

Según Borges, su poesía es lo que mejor le describe y es lo que señala las partes más íntimas y personales de su identidad. En la introducción a sus Selected Poems, el poeta deja clara la importancia de su obra poética:

First and foremost, I think of myself as a reader, then as a poet, then as a prose writer. [...] My stories are, in a sense, outside of me. I dream them, shape them, and set them down; after that, once set out in the world, they belong to others. All that is personal to me, all that my friends good-naturedly tolerate in me - my likes and dislikes, my hobbies, my habitsare found in my verse. In the long run, perhaps, I shall stand or fall by my poems. (XV-XVI) ${ }^{2}$

Si el poeta mismo declara que todo lo que le es más personal se encuentra en sus poemas, seguramente el crítico de Borges - para entender a Borges y para investigar cualquiera de sus escritos- tendrá que fijarse detalladamente en su obra poética. Y esta poesía constituye una parte sustancial de sus obras completas. Las obras de Borges se pueden dividir en tres etapas: la primera se compone mayormente por las colecciones de poemas como Fervor de Buenos A ires, L una de enfrente, y Cuaderno San Martín (todos escritos antes de 1930); la segunda etapa tiene la mayoría de sus obras narrativas como Ficciones y E 1 aleph (entre 1930-1959); y la tercera etapa repre-

${ }^{2}$ [Antes que nada, me pienso como un lector, luego como un poeta y después como un escritor de prosa. [...] Mis cuentos están, en cierto sentido, fuera de mí. Los sueño, les doy formay los escribo; después de eso, ya en el mundo, pertenecen a los demás. Todo lo que me es personal, lo que mis buenos amigos toleran en mí - mis gustos y mis disgustos, mis pasatiempos, mis hábitos- se encuentra en mi poesía. D espués de todo, quizás, me juzgarán por mis poemas]. 
senta una vuelta a la poesía con obras como El hacedor, El otro, el mismo, E logio de la sombra, La rosa profunda y La moneda de oro (de 1960-1976). Claro está que el poeta veía una importancia fundamental en la poesía ya que empieza su carrera literaria con poemas y regresa a la lírica en sus años más tardíos.

Como ya se ha mencionado arriba, los gustos, hábitos y preocupaciones del autor se encuentran en sus poemas. Estas obsesiones se manifiestan en una nostalgia por un tiempo pasado o mítico, el espacio de la ciudad y la identidad del poeta. Sin embargo, al final, estas cosas quedan inestables, inexistentes o irreales. La nostalgia espacial fracasa al presentar como objeto principal la ciudad de Buenos Aires que queda oscura, vacía y en silencio - un lugar de pura soledad; la nostalgia temporal (en la que vemos un vaivén entre la memoria de un pasado histórico ilusorio y un momento presente contemporáneo) va hacia una historia que es más mito y deseo proyectado que realidad; y la nostalgia del ser unificado y racional está dominada por una fragmentación y confusión o multiplicidad de identidad.

Puesto que las primeras dos obsesiones, el tiempo y el espacio, se han tratado bastante en conexión con los poemarios Fervor de Buenos A ires y C uaderno San M artín, no concentro mi análisis en ellas. Es interesante notar que dentro de la crítica sobre la poesía de Borges, la mayor parte se enfoca en temas de tiempo y espacio en estas primeras colecciones y no se preocupa tanto de las ricas colecciones tardías. Aquí me concierne la poesía tardía del poeta y cómo la obsesión de la identidad se manifiesta no solamente como un tema principal en dichos poemas, sino también la manera en que esta obsesión se desdobla en preocupaciones y cuestiones formales. A la vez, la obsesión de la identidad y el interés en cómo se constituye el yo resultan más profundas que las otras porque se relacionan con todas las otras preocupaciones que el poeta tiene, especialmente con las de cuestiones temporales y espaciales. A fin de cuentas, lo que la poética afirma es una identidad no estable y un yo que está en flujo continuo; lo que Deleuze y Guattari llaman una producción nómada y rizomática. Esta obsesión por la identidad esquizofrénica es justamente lo que niega una definición unita- 
ria o fija de su poética. Al analizar la poesía de Borges dentro de tal esquema deleuziano podremos comprobar la poética borgeana como una poética de identidades múltiples y formas fugitivas.

En los poemas que se analizarán aquí ("Borges y yo", "Los enigmas", "El instante, "Yo", "Al espejo" y "Heráclito") se pondrá a prueba que el yo poético afirma una inestabilidad de identidad y una continua evolución del ser. Pero es clave reconocer que esta evolución no va hacia un final determinado, sino que es un constante vaivén y flujo del ser en el tiempo y el espacio. Además, se propone un yo en el proceso de devenir otro, múltiple y esquizofrénico. Es así que Borges celebra un yo múltiple productivo, es decir, un yo en constante flujo y en interminable producción de nuevos yos. Esta identidad cuasi-subversiva también se desdobla en una forma revolucionaria del poema en prosa de los poemarios E logio de la sombra y E 1 hacedor. En "Borges y yo", (de E 1 hacodor) por ejemplo, no solamente se ven las tensiones productivas de una identidad múltiple como aquellas a las que ya aludí, sino que también la forma ambigua del poema en prosa dentro de una colección de poemas tiene cualidades literarias esquizofrénicas o múltiples. Lo que se verá aquí, entonces, es que al examinar a Borges dentro de un esquema esquizoanalítico se podrá comprobar y destacar las preocupaciones de identidad y cómo el desarrollo de tales obsesiones constituye la esencia indefinible y fugaz de la poética borgeana.

\section{Recurrencias: obsesiones con la fuga}

Se puede explorar la obsesión en términos psicológicos y filosóficos tanto como antropológicos y literarios. Lo que sí es clave es que la obsesión tiene que ver con los deseos, las preocupaciones y la intimidad. Por eso la poesía de Borges es tan importante en el estudio de la obsesión, porque en ella se nos presenta la intimidad del poeta y su interior. Podemos ver que la poesía de Borges nos da una perspectiva íntima a la vida y las preocupaciones del autor mismo y que "all poetry is autobiographical in the sense that it reflects the 
concerns and perspectives of its creator" (Brown 204). ${ }^{3}$ Y más que nada son sus poemas posteriores que son de mucho interés aquí porque están aun más vinculados con las obsesiones del poeta. Como señala Jaime Alazraki,

El aparente impersonalismo de sus primeros libros define una verdadera estética del pudor y del gesto épico. Estos temas reaparecen en sus últimas colecciones, pero en ellas Borges explora un tema apenas enunciado en su poesía anterior: la intimidad del hombre que trasciende la máscara del poeta. (145)

Aquí Alazraki detecta una diferencia notable entre las primeras colecciones de Borges que carecen de lo íntimo y las últimas colecciones en las que el poeta explora temas existenciales de identidad e intimidad. En vez de meterse en juegos y en tantas experimentaciones que son propios de sus primeros escritos ultraístas, la poesía tardía de Borges muestra una verdadera preocupación por temas filosóficos como la existenciay laidentidad. Como dice Armani: "los poemas iniciales de Borges, los que escribió en Europa en su primera juventud, carecen en general de interés, [...] carecían de un núcleo central; les faltaba la pasión de un motivo fundamental que les diera ese quid que el genio de la poesía solicita de sus servidores" (281). Es en los poemas tardíos que veremos la pasión y reflexión profunda sobre la identidad y sus obsesiones que, aunque aludan a un cierto tiempo y espacio, se fundamentan en las cuestiones de la construcción del yo.

Para Freud, los parámetros más significativos de la obsesión se centran en las cuestiones de la recurrencia y la ansiedad. Una neurosis obsesiva se manifiesta en las constantes repeticiones de una acción y a veces en la ansiedad o la preocupación extrema por el objeto 0 acción (Civilization 99). En A G eneral Introduction to

${ }^{3}$ [toda poesía es autobiográfica en el sentido de que refleja las preocupaciones y perspectivas de su creador]. 
Psychoanalyis Freud expone en gran detalle la cuestión de la obsesión clínica y sus varios síntomas. Dice: "the obsessional neurosis takes this form: the patient's mind is occupied by thoughts [...] and he is impelled to perform actions. [...] Against his will he has to worry and speculate as if it were a matter of life or death to him" (229). ${ }^{4} \mathrm{Y}$ a la vez que uno se preocupa y obsesiona por una cierta neurosis, le entran en la mente más ansiedades con respeto a la obsesión de manera que "doubt appears in the intellectual sphere" (230). ${ }^{5}$ Pero en nuestro análisis de Borges la obsesión no se basa en una ansiedad clínica ni en una enfermedad o trauma que necesita curación. La obsesión de Borges se funda más bien en la recurrencia de la representación de las preocupaciones ontológicas. Se basa en reflexiones y meditaciones sobre la existencia y la constitución del yo. En vez de anhelar un yo racional, curado de toda "enfermedad" obsesiva, en Borges se celebra un yo fugitivo. Mas es cierto que en cualquier situación 0 análisis "the obsessive act is full of meaning; it seems to be a representation, a repetition of that all important scene" (Freud, Introduction 233). ${ }^{6}$ Entonces, la obsesión definida por Borges se podría articular de la siguiente manera: la obsesión es lo que se repite, lo que se medita y lo que funda la base de la ansiedad del yo poético.

En los poemas de sus últimas colecciones que se verán aquí investigaremos la obsesión y la recurrencia de la inquietud del yo. Esta obsesión por la composición de la identidad le hace al yo poético contemplar el yo (y desarrollarlo) en términos de multiplicidades, rizomas, otredades y fugacidades. Y es precisamente esta poética de obsesiones basada en lo múltiple y lo fugaz que causa tantos problemas para una definición estable de la poética borgeana.

${ }^{4}$ [la neurosis obsesiva toma la siguiente forma: la mente del paciente está ocupada por pensamientos (...) y el paciente se ve obligado a actuar. (...) En contra de su voluntad el paciente tiene que preocuparse y especular como si ello fuera un asunto de vida o muerte].

${ }^{5}$ [la duda aparece en la esfera intelectual].

${ }^{6}$ [el acto obsesivo está repleto de sentido; parece ser una representación, una repetición del evento primordial]. 


\section{Deleuze y los rizomas}

Antes de entrar en un análisis de los poemas de Borges hemos de elucidar unos términos de D eleuze que nos servirán de base teórica para acercarnos a la poesía de Borges y poner a prueba sus obsesiones y preocupaciones de la identidad que afirman una identidad en constante línea de fuga de la estabilidad. El pensamiento estético de Deleuze se basa en ciertos principios fundamentales: el rizoma, la diferencia, las multiplicidades y el sujeto nómada. Todos éstos tienen como función subvertir normas tradicionales de la razón y deconstruir la estabilidad del pensamiento occidental que se basa en el control "totalitario". Al contrario, D eleuze celebra la fuga de formas y la inestabilidad del sujeto. Para Deleuze, es sólo por medio de esta esquizofrenia subversiva que el sujeto puede librarse de las imposiciones de una sociedad que intenta definir todo en términos de dominación. Es por eso que el esquizoanálisis deleuziano niega la importancia de lo molar (es decir, las construcciones fálicas universales de instituciones totalitarias como la iglesia, el gobierno y la familia edípica y sus jerarquías opresivas) en favor de lo molecular (lo local, lo que es más pequeño, siempre en flujo, y lo que no se fija ni se construye en formas dominantes). Deleuze y Guattari están en contra de las fijaciones totalitarias que resumen en A nti-0 edipus de la siguiente forma: "Let us recall the major traits of a molar function or of a form of gregariousness. They effect a unification, a totalization of the molecular forces through a statistical accumulation obeying the laws" (342). ${ }^{7}$

En este sentido el sujeto esquizofrénico es más preferible para le estética deleuziana que cualquier otro porque está fuera de la institución y no se vuelve paranoico por las imposiciones del orden simbólico. Es molecular, y como tal, siempre imperceptible, en fuga y en proceso interminable de devenir múltiple (A nti-0 edipus 28286). Por eso la esquizofrenia es el modelo por excelencia de la pro-

${ }^{7}$ [Recordemos los grandes rasgos de una formación molar o de una forma de gregarismo. Efectúan una unificación, una totalización de las fuerzas moleculares por acumulación estadística, obedeciendo a leyes (A ntiedipo 352)]. 
ducción del ser humano porque es capaz de expresar todos sus deseos y obsesiones. Pero aquí no se trata de una esquizofrenia clínica sino de una esquizofrenia activa que produce yos nuevos y múltiples. Según D eleuze y Guattari,

This reversal side is the "real inorganization" of the molecular elements: partial objects that enter into indirect syntheses or interactions, since they are not partial in the sense of extensive parts, but rather partial like the intensities under which a unit of matter always fills space in varying degrees; pure positive multiplicities where everything is possible, without exclusiveness or negation. (A nti-0 edipus 309) ${ }^{8}$

Esta celebración de la diferencia se expone en las teorías sobre el rizoma que trata de una raíz que crece de manera horizontal y no vertical. No establece jerarquías ni dependencia en otras partes de la raíz. Además, el rizoma se puede romper y de repente puede volver a crecer. Puede conectarse y desconectarse con cualquier otra parte de la raíz y establecer un sistema en constante cambio y fuga. Empleando la metáfora del rizoma, D eleuze y Guattari exponen el sujeto nómada que se trata de un yo en constantes líneas de fuga. En vez de una identidad como un proceso desde un punto A hasta un punto B, el sujeto rizomático "rejects any idea of pretraced destiny, whatever name is given to it - divine, anagogic, historical, economic, structural, hereditary, or syntagmatic" (Plateaus 13). ${ }^{9}$

Es de esta manera, entonces, que D eleuze y Guattari establecen una teoría del yo esquizoide que está en fuga constante. El intento de subvertir el pensamiento platónico que busca lo ideal y lo racio-

${ }^{8}$ [Este reverso es la "inorganización real" de los elementos moleculares: objetos parciales que entran en síntesis o interacciones indirectas, puesto que no son parciales en el sentido de partes extensivas, sino más bien "parciales" como las intensidades bajo las que la materia llena siempre el espacio en diversos grados; puras multiplicidades positivas en las que todo es posible, sin exclusiva ni negación. (A nti-E dipo 319)].

${ }_{9}^{9}$ [rechaza cualquier idea de fatalidad calcada, sea cual sea el nombre que se le dé, divina, anagógica, histérica, económica, estructural, hereditaria o sintagmática (M ese tas 18)]. 
nal se manifiesta en la proposición de un yo que rompe las reglas del cogito cartesiano estable. Este rompimiento afirma un antiplatonismo que celebra las copias, el simulacro y lo múltiple. En The L ogic of Sense D eleuze expone su disgusto con el platonismo: "The popular and technical images of the philosopher seem to have been set by Platonism: the philosopher is a being of ascents; he is the one who leaves the cave and rises up. The more he rises the more he is purified" (127). "Pero D eleuze propone una caída o inversión de tal pensamiento: "What does it mean 'to reverse Platonism'? [...] The formula seems to mean the abolition of the world of essences and the world of appearances" (253). ${ }^{11}$ Se afirma más bien "a becoming always other, a becoming subversive of the depths, able to evade the equal, the limit, the Same, or the Similar. [...] To impose a limit of this becoming [...] is the aim of Platonism in its will to bring about the triumph of icons over simulacra" (258-9). ${ }^{12}$ D eleuze deja claro aquí que se afirma el doble, la copia, la diferencia, la multiplicidad y lo esquizoide. Todo ello para subvertir lo molar (nuclear) y lo institucional al afirmar una búsqueda de la creatividad artística basada en la producción esquizofrénica liberada de dominación.

\section{El caso de Borges: poemas rizomáticos y poéticas de obsesión}

Tal vez en Borges no se trata de una subversión tan extrema como se ve en D eleuze y Guattari, sin embargo el esquizoanálisis provee

${ }^{10}$ [La imagen del filósofo, tanto la popular como la científica, parece haber sido fijada por el platonismo: un ser de las ascensiones, que sale de la caverna, se elevay se purifica cuanto más se eleva (L ógica 139)].

${ }^{11}$ [¿Q ué significa 'inversión del platonismo'? (...) Parece como si la fórmula quisiera decir: la abolición del mundo de las esencias y del mundo de las apariencias" (L ógica 255)].

${ }^{12}$ [un devenir siempre otro, un devenir subversivo de las profundidades, hábil para esquivar lo igual, el límite, lo Mismo, o lo Semejante. (...) Imponer un límite a este devenir (...) es el objetivo del platonismo en su voluntad de hacer triunfar los iconos sobre los simulacros (L ógica 260)]. 
un modelo importante con que se pone a prueba la poética de Borges, su escapatoria de la definición y la obsesión con la identidad rizomática. La obsesión con la identidad comienza en "Borges y yo" de E 1 hacedor (1960), una de las obras borgeanas más comentadas. De primer interés en "Borges y yo" es la forma literaria que se emplea en la que se ve una subversión de la tradición literaria al eliminar la oposición entre la prosa y la poesía. En este poema en prosa la distinción entre ensayo, relato, poema y cuento corto se borra. Según Di Giovanni,

One of the celebrated aspects of Borges' style has been his frequent blurring or abolishment of the boundaries between the short story and essay forms. [...] Similarly, Borges draws no great distinction between his poems and a number of his short prose pieces, often disclaiming any essential difference between prose and poetry at all and saying that he writes the one or the other merely to suit private needs or moods. (Citado en Borges, Selected Poems 255) ${ }^{13}$

Mucha de la poesía tardía de Borges favorece esta mezcla de diferentes estilos genéricos como se ven abundantemente en El hacedor y E logio de la sombra (1969). Esta "alternancia de prosa breve y poesía - la hibridación y mezcla de registros genéricos" (Fernández 68), ejemplifica lo que D eleuze afirma como una escritura esquizofrénica que no respeta límites ni géneros. Esta colección representa el comienzo de la poesía tardía de Borges y en ella se ven íntimas reflexiones sobre temas como la identidad y su multiplicidad. Es decir, la forma esquizofrénica de "Borges y yo" desdobla un contenido esquizofrénico en que el yo lírico siempre deviene

${ }^{13}$ [Uno de los aspectos celebrados del estilo borgeano ha sido el frecuente borramiento o la frecuente abolición de las fronteras entre el cuento corto y el ensayo. [...] Del mismo modo, Borges no realiza una gran distinción entre sus poemas y varios de sus obras cortas de prosa, muchas veces negando cualquier diferencia esencial entre la prosa y la poesía y afirmando que escribe de una u otra forma simplemente para satisfacer sus necesidades o humores privados]. 
otro o múltiple. Con "Borges y yo" se ve que "The first schizophrenic evidence is that the surface has split open. Things and propositions have no longer any frontier between them" (D eleuze, The L ogic of Sense 86).$^{14} \mathrm{~A}$ partir de $\mathrm{E} l$ hacedor no hay delimitaciones ni fijaciones en la poética de Borges. Al contrario, se afirma una poética de obsesiones por lo múltiple.

En "Borges y yo" se ve una tensión entre el Borges-escritor y el Borges-hombre. Es importante comentar el título de la colección, El hacedor, que hace al lector reflexionar sobre el creador del acto poético y los múltiples niveles de su identidad. En "Borges y yo" el escritor y el hombre se contrastan, se mezclan y se confunden. Al final, como es evidente en la última línea, ni siquiera se sabe quién es el hacedor. Este título, junto con la forma rizomática a la que ya aludí, habla sobre el contenido del poema y la obsesión con el hacedor lírico inestable (e indefinido), y sus repetidas manifestaciones que siguen hasta los últimos poemas del poeta.

Este poema comienza con un yo lírico (¿o el Borges-hombre?) refiriéndose al Borges-autor. Habla sobre este otro "a quien le ocurren las cosas," y reconoce las diferencias y las semejanzas entre los dos. Dice que los dos prefieren "los relojes de arena, los mapas, la tipografía del siglo XVIII, las etimologías, el sabor del café y la prosa de Stevenson" pero hay unas diferencias en cómo cada uno manifiesta tales preferencias. El yo es más humilde en sus deseos mientras el álter ego prefiere las cosas de manera vanidosa e hipócrita. Regazzoni resume esta relación diciendo que "A es vanidoso, transformador, actor, tramador, perverso, falseador, magnificador, escribe libros; B es el que camina, que mira, que gusta, que se deja vivir. Con la letra $C$ se puede resumir los términos comunes" (44). Es decir, son la misma persona y otras personas a la vez. Así, los dos se confunden y se mezclan. De los dos, el yo lírico es sumamente ambiguo porque se puede referir al Borges-hombre tanto como a muchos otros como analiza Reyes Pérez:

${ }^{14}$ [La primera evidencia esquizofrénica es que la superficie ha reventado. Ya no hay frontera entre las cosas y las proposiciones (L ógica 103)]. 
Sabemos quién es el "otro", lo sabemos en la personalidad del Borges poeta. Pero preguntémonos quién es "yo". Acaso nos cruzaremos con Borges el hombre o con el lector anónimo en español y en diversas lenguas en las que el poeta ha sido traducido. [...][el yo] se sabe absorbido progresivamente por el "otro", el Borges poeta, y como en él, en el múltiple, resuena la pluralidad de la especie humana. (42)

En "Borges y yo" el escritor muestra una preocupación por la constitución del yo y por el hecho de que dentro de cada uno de nosotros hay muchos otros. Borges mismo alude a los muchos otros que hay dentro de él cuando le preguntan sobre los múltiples seres de "Borges y yo": "I suppose we are all in a sense Dr. Jekylls and Mr. Hydes, any amount of Jekylls and any amount of Hydes, and a lot of others thrown in between" (Stern 3). ${ }^{15}$ Esta esquizofrenia poética a la que alude Borges coincide con las primeras líneas que escriben D eleuze y Guattari en A Thousand Plateaus, cuando hacen referencia a la tarea de escribir y la importancia de las múltiples identidades en la producción creativa: "The two of us wrote A nti0 edipus together. Since each of us is several, there was already quite a crowd" (3). ${ }^{16}$ La ambigüedad e inestabilidad del yo poético crea un dilema existencial que se manifiesta como obsesión repetitiva. Hablando de los seres múltiples que se manifiestan en "Borges y yo" Barnstone reconoce que

In these multiple creations of creations, we find the essential dilemma in Borges: Borges is a character created by Borges who will always escape into a new creation; but no sooner will he become the other, el otro, the yo of Borges y yo, no sooner does that shy man Borges wielding a mighty club of

${ }^{15}$ [Supongo que, en cierto sentido, todos somos varios doctores Jekyll y señores Hyde, cualquier cantidad de Jekylles y cualquier cantidad de Hydes, y muchos otros también].

${ }^{16}$ [E 1 A nti-E dipo escribimos a dúo. Como cada uno de nosotros era varios, en total ya éramos muchos" (M esetas 9)]. 
modesty shift into the writer and into a text [...][and we] lose track that Borges can return once more to that original Borges, whoever he is, and start again. (134-35) ${ }^{17}$

Aquí se ven las constantes referencias a un Borges (o mejor dicho, muchos Borges) que están en evolución incesante; cambiando, volviéndose (deviniendo) múltiples y siguiendo un patrón rizomático. Barnstone continúa:

From all this I wish to propose that Borges is a very unstable compound, a mysterious compound, who searches relentlessly to find a stable single condition, a label or formula or key to his essence, but is one fated to eternal metamorphosis. Like space abhorring a vacuum, Borges abhors a condition of stasis. For this reason he moves from enstasis (being in himself) to ekstasis (being elsewhere). As the poet of ecstasy, he is fated to follow the voyage of the seeker, not the finder, to wander, following the original Greek usage of the word ekstasis, "outside himself." [...] The protean Borges cannot be formulated and pinned against a wall of reality or illusion. [...] Borges' central obsession is Borges: how to get away from that "coward and pedant" he knows too well. (135-36) ${ }^{18}$

${ }^{17}$ [D entro de estas múltiples creaciones de creaciones, encontramos el dilema esencial de Borges: Borges es un personaje creado por Borges quien siempre se escapará hacia una nueva creación; pero tan pronto como deviene otro, el otro, el yo de Borges y yo, tan pronto como el hombre tímido llamado Borges empuña un poderoso garrote de modestia llega a ser un escritor dentro del texto (...)[y] perdemos la cuenta de qué Borges puede volver a ser aquel Borges original - cualquiera que seay comenzarlo todo de nuevo].

${ }^{18}$ [D e todo esto quiero proponer que Borges es una entidad compleja muy inestable, un ente misterioso, que busca implacablemente encontrar una condición estable, una fórmula o clave de su propia esencia, que, sin embargo, está condenada a una metamorfosis eterna. Como el espacio que aborrece el vacío, Borges aborrece una condición de stasis. Por esta razón se mueve de enstasis (ser en sí mismo) a ek stasis (ser fuera de sí). Como poeta del éxtasis, está condenado a seguir el camino del buscador, no del que encuentra, sino del que vaga, tomando el sentido original dela 
Entre el Borges-escritor, el Borges-hombre y el yo poético no se puede definir precisamente quién es el hacedor o creador de lo que se ha dejado en la página. El poema nos hace deducir que el creador artístico, tanto como el yo poético y el autor de carne y hueso, son un conjunto de muchas tensiones productivas y varios múltiples yos. Estas escapatorias crean muchos problemas cuando uno intenta definir una poética que no puede ser "formulated and pinned against a wall of reality" (Barnstone 136). ${ }^{19}$

O tra referencia clave del poema "Borges y yo" es la que se hace a Spinoza: "Spinoza entendió que todas las cosas quieren perseverar en su ser; la piedra eternamente quiere ser piedra y el tigre un tigre. Yo he de quedar en Borges, no en mí (si es que alguien soy)". Esta referencia a Spinoza es una de por lo menos tres en la poesía borgeana. Borges tiene un poema titulado "Spinoza" en El otro, el mismo (1964) y otro llamado "Baruch Spinoza" en La moneda de hierro (1976). Borges se relaciona con "Las traslúcidas manos del judío/ [que] Labran en la penumbra los cristales" (de "Spinoza") porque los dos son artesanos que trabajan una materia: Spinoza, las ideas y los cristales; y Borges, las palabras. Spinoza (sí mismo un yo-como-otro siendo judío holandés de familia portuguesa) trabajaba con cristales pensando todo el día en los misterios del ser y del más allá para poder filosofar con sus contemporáneos por la noche. Borges también trabaja su materia poética al intentar dominarla y someterla a una forma que profundiza las cuestiones del ser y del yo. El pensamiento spinozista incluye profundas cuestiones existenciales sobre el ser humano y su inmanencia:

La mente humana, a juicio de Spinoza, pierde en amplia medida su potencia, cuando se deja dominar por las afecciones.

palabra griega ek stasis, "ser fuera de sí". [...] El Borges proteo no puede ser pensado 0 encorsetado ni dentro de lo real ni dentro de lo ilusorio. [...] La obsesión central de Borges es Borges mismo: cómo alejarse del "cobarde y pedante" a quien él conoce demasiado bien].

${ }^{19}$ [formulada ni sujetada contra un muro de realidad]. 
Prevalecen en ella las ideas inadecuadas, es decir, las que tienen su fuente en la experiencia. En este nivel son fragmentarias y confusas.

Los hombres, hay que insistir en ello, niegan su presencia en el mundo, desperdician su energía, en el momento en que las cosas concretas los conmueven y los torturan. En vez de optar por la forma de conocimiento que genera las ideas adecuadas, las que aseguran un conocimiento completo del esquema necesario que distingue al orden natural, infinito, eterno y autogenerante, se vuelcan en los intereses transitorios. (Castro López 42-43)

Para Spinoza toda realidad es una sustancia que reside dentro del ser y que tiene un número infinito de atributos y posibilidades. D entro del Uno está toda característica posible. No es sorprendente que D eleuze también se interesa en Spinoza y deduce que dentro del pensamiento spinozista "each individual is an infinite multiplicity, and the whole of Nature is a multiplicity of perfectly individuated multiplicities. [...] [And] the $\mathrm{O}$ ne is said with a single meaning of all that is multiple" (Plateaus 254). ${ }^{20}$

El yo de "Borges y yo" no tiene otro remedio que dejarse fugar y devenir otro como leemos en la penúltima línea del poema: "Así mi vida es una fuga y todo lo pierdo y todo es del olvido, o del otro." Estas palabras confirman la obsesión de identidad fugaz como se ve en la poética tardía de Borges. Todo queda irresuelto y fragmentado. El yo no puede afirmar una identidad racional ni estable al optar por una serie de escapatorias. Este poema combate al yo racional y la estabilidad del verbo "ser". Al contrario, el ser está en un constante proceso de devenir más y en términos deleuzianos "the fabric of the rhizome is the conjunction, 'and . . . and . . . and ...' This conjunction carries enough force to shake and uproot the verb

${ }^{20}$ [cada individuo es una multiplicidad infinita, y la Naturaleza en su conjunto una multiplicidad de multiplicidades perfectamente individuada. [...][Y] lo Uno se dice en un solo y mismo sentido de todo lo múltiple (M esetas 258-259)]. 
'to be"' (Plateaus 25). ${ }^{21}$ Silvay G utiérrez han afirmado que en "Borges y yo", "La escritura borgeana habilita los márgenes, la circularidad, pero también se disemina, o como diría Gilles D eleuze, en momentos se transforma en una escritura rizomática" (4). En "Borges y yo" se ve que la obsesión con la identidad se manifiesta con la tensión esquizofrénica entre los varios Borges y que esta obsesión poética afirma un yo en fuga que resiste la fijación.

\section{Los otros de uno mismo}

La próxima colección de poesía borgeana, E l otro, el mismo (1964) sigue esta trayectoria de preocupaciones por la identidad y su inestabilidad. D e nuevo, el título de la colección revela mucho en cuanto a estas obsesiones del poeta. Se podría leer este título de muchas maneras: el otro y el mismo, el otro o el mismo, el otro es el mismo, el otro en el mismo o ni el otro ni el mismo. En cualquiera de estas frases se ve que Borges alude no sólo a la relación entre uno mismo y el otro sino también a la relación entre uno mismo y su propio yo, es decir, entre las múltiples facetas de uno mismo. También señala que estas relaciones pueden ser ambiguas y en flujo. Los poemas de esta colección repiten la preocupación del título al marcar que "la frontera entre el yo y los otros es una franja inestable, donde las identidades se desestabilizan" (Moraña 268).

El poema "Los enigmas" presenta un yo lírico y sus meditaciones sobre los enigmas del ser y de la eternidad:

Yo que soy el que ahora está cantando

Seré mañana el misterioso, el muerto,

El morador de un mágico y desierto

Orbe sin antes ni después ni cuándo. (1-4)

${ }^{21}$ [el rizoma tiene como tejido la conjunción 'y ... y ... y ...' En esta conjunción hay fuerza suficiente para sacudiry desenraizar el verbo 'ser' (M esetas 29)]. 
Aquí el lector ve un yo que no solamente está en flujo sino que además se preocupa por el tiempo y su propia relación con un tiempo que cambia. La obsesión por el yo fugaz se desdobla en un tiempo cambiante, en el que no existe ni un "antes ni después ni cuándo." El yo lírico afirma esta identidad que ahora es una cosa y mañana otra al decir que "Nuestra historia/ cambia como las formas del Proteo" (7-8). El yo está dentro de un tiempo y una historia que están en constante proceso de devenir otro y que dentro de los cuales el yo no tiene otro remedio que involucrarse en el mismo proceso interminable. Al pensar sobre el pasado y el momento presente el yo entiende que, como deduce Henri Bergson, "what I call 'my present' has one foot in my past and another in my future [...] [and it] represents the actual state of my becoming" (138). ${ }^{22}$ Es decir que el yo contempla su existencia en términos de un tiempo que es fugaz y construido por factores rizomáticos. Y en el último verso del poema el yo ve que al morir podrá "Ser para siempre; pero no haber sido" (14). La obsesión con la identidad inestable hace al yo contemplar los enigmas de su tiempo, su muerte y su memoria.

Esta preocupación temporal del yo en relación con su propia identidad también se manifiesta en "El instante". Aquí el tiempo es el agente que cambia al yo y que le hace dudar del engaño del reloj. Comienza con una pregunta sobre el tiempo pasado y en dónde figura el yo dentro de aquél:

¿Dónde estarán los siglos [...]

?

El presente está solo. La memoria

erige el tiempo. Sucesión y engaño

Es la rutina del reloj. [...]

El rostro que se mira en los gastados

Espejos de la noche no es el mismo.

El hoy fugaz es tenue y es eterno;

O tro Cielo no esperes, ni otro Infierno. (1-14)

22 [lo que yo llamo 'mi presente' particip[a] a la vez de mi pasado y de mi porvenir (...) [y] representa, pues, bien el estado actual de mi devenir (M ateria 179-180)]. 
"El instante" da reflexión sobre el momento presente y la memoria del pasado. Al final la voz poética medita sobre un presente perpetuo. Para Bergson, el asunto del tiempo tiene mucho que ver con la identidad fugaz porque "the normal self never stays in either of these extreme positions [the present and the past]; it moves between them" (163). ${ }^{23}$ La cuestión temporal del poema es clave porque el yo no puede negar su existencia temporal (ni espacial), pero a la vez entiende que es el tiempo mismo lo que lo cambia en cada instante. El instante fugaz de este poema es aquel en que el yo reconoce que, al verse en el espejo, es siempre otro. Este yo esquizoide y cambiante en el tiempo es, en términos deleuzianos, "A rhizome [that] has no beginning or end; it is always in the middle, between things, interbeing, intermezzo" (Plateaus 25). ${ }^{24}$ El sujeto siempre está en flujo dentro de su instante temporal. Este proceso de constantes devenires del yo y del tiempo es fundamental en la obsesión de Borges con el yo.

\section{El yo y el doble}

La rosa profunda (1975) también reflexiona sobre la obsesión con la construcción inestable y múltiple del yo. En el primer poema, "Yo", la voz lírica describe las cosas comunes (y crípticas) que forman el yo. Este yo es parte de su mundo y todo lo que le rodea es parte de él.

La calavera, el corazón secreto,

Los caminos de sangre que no veo,

Los túneles del sueño, ese Proteo,

Las vísceras, la nuca, el esqueleto.

Soy esas cosas. Increíblemente

Soy también la memoria de una espada (1-6)

${ }^{23}$ [el yo normal no se fijajamás en una de estas posiciones extremas [el presente y el pasado]; se mueve entre ellas (M ateria 214)].

${ }^{24}$ [Un rizoma [que] no empieza ni acaba, siempre está en el medio, entre las cosas, inter-ser, intermezzo (M esetas 29)]. 
Es decir, el yo es todo lo que lo constituye tanto física como metafísicamente (el secreto, el sueño, la memoria) pero también todo lo que hay en el mundo como "los contados libros, los contados/ Grabados [...]" (10-11). Todo es parte de él. Este yo múltiple es un yo que cambia forma como el Proteo y "que se dispersa en oro, en sombra, en nada" (8). Pero la preocupación más profunda del yo lírico en cuanto al "Yo" se ve en los últimos versos cuando proclama: "Más raro es ser el hombre que entrelaza/ Palabras en un cuarto de una casa" (13-14). De nuevo (como en "Borges y yo") el yo lírico intercala el yo-escritor en el poema al referirse al ser que escribe las palabras. Ser un yo-poeta resulta una experiencia rara para el yo lírico; una experiencia en la cual el yo medita sobre la rareza de su propia fugacidad y multiplicidad.

"Al espejo" (de L a rosa profunda) también elabora los yos múltiples y afirma un antiplatonismo de sombras, copias y reflejos. El espejo para Borges es un motivo central de su obsesión con la identidad. Como niño, Borges tenía una fascinación con el espejo y su doble (Zubizarreta 378), pero a la vez sentía una cierta ansiedad cuando se miraba en él. Esta oposición binaria de atracción y horror crea un sentimiento que Freud llama "lo siniestro." Es algo que presenta lo familiar pero que enajena a uno de sí mismo a la vez. Según el poeta,

mirrors are very strange things. Mirrors give you the sense of the double. They give the Scottish wraith. When a man sees himself, according to Scottish superstition, he is about to die. His real self comes to fetch him back. [...] As for two Borges, I have been made keenly aware of the fact that there are two, because when I think of myself I think, let us say, of a rather secret, of a rather hesitant, groping man. [...] the private man, and the public man. (Yates 197)25

${ }^{25}$ [los espejos son cosas muy extrañas. Los espejos aportan el sentido del doble. Construyen el espectro escocés. Cuando un hombre se ve, según la superstición escocesa, está a punto de morir. Su ser real viene a buscarlo o a capturarlo. (... ) En cuanto a los dos Borges, sé muy bien que, de hecho, son dos porque cuando reflexio- 
En "Al espejo" el lector ve la ansiedad del yo lírico delante del espejo. El poema comienza con una interrogación dirigida a la persistencia del espejo.

¿Por qué persistes, incesante espejo?

¿Por qué duplicas, misterioso hermano,

El menor movimiento de mi mano?

¿Por qué en la sombra el súbito reflejo?

Eres el otro yo de que habla el griego (1-5)

Lo que comprueba la obsesión con la identidad de Borges es precisamente su introspección sobre su reflejo y las varias copias de sí mismo. Ve a su "otro yo" y al verlo, entiende que el yo se constituye por muchos. El papel del espejo es mostrar al hombre que su reflejo es otro yo y que cada uno tiene muchas facetas. El espejo "Multiplic[a] la cifra de las cosas/ Q ue somos" (11-12). Borges afirma la multiplicidad del yo y muestra que cada intento de comprender al yo termina en un entendimiento de que el yo es construido por copias, sombras y fugas.

\section{Heráclito y una poética de la obsesión}

La preocupación y obsesión con la identidad llega a su culminación en el poema "Heráclito" de L a moneda de hierro (1976), la penúltima colección de Borges. En E logio de la sombra (1969) hay otro poema que lleva el mismo título. Referencias continuas a Heráclito se encuentran también en otros poemas y prosas borgeanas. Borges capta la identidad como obsesión en el motivo del flujo del río al cual alude Heráclito. Tal río de constante flujo y de movimiento continuo es una metáfora del ser nómada al que hacen referencia D eleuze y Guattari. Para ellos el nómada es un ser autónomo que existe en

no sobre yo mismo considero, digamos, que hay un hombre tentativo y anhelante. (...) el hombre privado y el hombre público]. 
un sinfín de fugas y multiplicidad de posibilidades (Plateaus 404415). En el poema de Borges "Heráclito camina por la tarde / De Éfeso. La tarde lo ha dejado,/ Sin que su voluntad lo decidiera" (1-3). $\mathrm{El}$ ser heraclitano se fuga como nómada sin voluntad. La vida le lleva por cualquier lado. La voz de Heráclito declara que "N adie baja dos veces a las aguas/ Del mismo río" (11-12). Aquí el yo contempla la fugacidad de Heráclito y no solamente el flujo constante del río, sino también el flujo del ser y la imposibilidad de sumergirse dos veces en las mismas aguas de un río, porque todo (tanto el ambiente como el ser) está en una cadena de fugas. El yo poético declara que "él también es un río y una fuga. [...][y que] Heráclito no tiene ni ayer ni ahora" $(14,22)$. Para Heráclito, tanto como para Borges, la vida, la identidad y el tiempo están en fuga y flujo. En "Heráclito", de E logio de la sombra, el yo manifiesta la misma obsesión de la siguiente manera: "El río me arrebata y soy ese río" (23). El motivo del río, el cual señala el flujo de la identidad, también es central en el poema "Arte poética" de El hacedor. En este poema el yo lírico quiere

Mirar el río hecho de tiempo y agua

Y recordar que el tiempo es otro río,

Saber que nos perdemos en el río

Y que los rostros pasan como el agua. (1-4)

El yo poético borgeano se constituye precisamente por su propia inestabilidad y multiplicidad. Al afirmar una identidad de diferencias y rizomas esta poética reformula la lógica occidental del yo que se centra en el logocentrismo y el idealismo platónico. Como dice Beatriz Sarlo "la literatura de Borges es de frontera: vive de la diferencia" (108). Es por eso que es difícil encerrar la obra poética de Borges y definirla como algo estable y racional. Lo que he puesto a prueba aquí es que la poética de Borges evade tal encerramiento al obsesionarse con identidades de constante fuga y devenires. El crítico de Borges, entonces, sólo puede acercarse a esta poética al examinarla en términos de su preocupación por identidades múltiples y el flujo; en términos que subvierten las definiciones estables 
de la identidad y de la poética. En la poética de Borges "todo es como el río de Heráclito, que no es nunca el mismo río, fluyendo, cambiando cada partícula de agua que es en sí otro río y el mismo río, sin cesar transformándose sinuosamente en su eterno curso" (Shellhorse 9). Borges ejemplifica el anhelo deleuziano por las partículas moleculares que celebran un yo fugaz, otro y esquizoide que siempre está en el proceso de devenir múltiple. Este ser niega todo lo que es estable y molar (nuclear). En su ensayo L a nueva refutación del tiempo Borges sintetiza la obsesión con las fugas de tiempo e identidad de la siguiente forma:

Negar la situación temporal, negar el yo, negar el universo astronómico, son desesperaciones aparentes y consuelos secretos. Nuestro destino [...] no es espantoso por irreal; es espantoso porque es irreversible y de hierro. El tiempo es la sustancia de que estoy hecho. El tiempo es un río que me arrebata, pero yo soy el río; es un tigre que me destroza, pero yo soy el tigre; es un fuego que me consume, pero yo soy el fuego. El mundo, desgraciadamente, es real; yo, desgraciadamente, soy Borges. (Citado en Amores de Pagella 108)

La preocupación y obsesión con quién es el yo es clave en la poética borgeana. Esta obsesión con la existencia penetra la obra poética de las colecciones posteriores a través de las fugacidades formales y genéricas de los poemas prosaicos, las fugas de identidades que afirman los yos múltiples y los yos líricos que se manifiestan como ríos y rizomas.

\section{Bibliografía}

Alazraki, Jaime. "El difícil oficio de la intimidad." Borges como poeta. Ed. Ángel Flores. México D. F.: Siglo Veintiuno, 1984. 145-68. Amores de Pagella, Ángela Blanco. "Los temas esenciales." Borges como poeta. Ed. Ángel Flores. México D. F.: Siglo Veintiuno, 1984. 89-108. 
Armani, Horacio. "Evolución de la poesía borgeana." Boletín de la A cademia A rgentina de L etras 241-242 (1996): 281-90.

Barnstone, Willis. "Borges, Poet of Ecstasy." Borges the Poet. Ed. Carlos Cortínez. Fayetteville: U of Arkansas P, 1986. 134-41.

Bergson, Henri. Matter and M emory. Trans. Nancy Margaret Paul and

W. Scott Palmer. New York: Zone Books, 1991. Edición en español: Materia y memoria. Trad. Martín Navarro. Madrid: Victoriano Suárez, 1900.

Borges, Jorge Luis. 0 bras completas. Buenos Aires: Emecé, 19891996.

Selected Poems: 1923-1967. Ed. Norman Thomas Di

Giovanni. New York: Delacorte, 1972.

Brown, Bonnie M. "The Poetry of Jorge Luis Borges: A Revelation

Not Yet Produced." H ispania 67.2 (1984): 201-206.

Casabona, Alberto N. Introducción al pensamiento estético de G illes

D eleuze. Valencia: Tirant Lo Blanch, 2001.

Castro López, O ctavio. "Borges y Spinoza: la É tica en una castaña." Tex to Crítico 4.8 (2001): 35-49.

Deleuze, Gilles and Félix Guattari. A nti-0 edipus: C apitalism and Schizophrenia. Trans. Robert Hurley, Mark Seem, and Helen R. Lane. Minneapolis: U of Minneapolis P, 1983. Edición en español: E 1 A nti-E dipo: C apitalismo y esquiz ofrenia. Trad. Francisco Monge. Barcelona: Paidós, 1985.

. A Thousand Plateaus: Capitalism and Schizophrenia. Trans.

Brian Massumi. Minneapolis: U of Minneapolis P, 1987. Edición en español: M il mesetas: Capitalismo y esquizofrenia. Trad. José Vázquez Pérez. Valencia: Pre-Textos, 2000.

D eleuze, G illes. The L ogic of Sense. Trans. Mark Lester and Charles Stivale. Ed. Constantin Boundas. New York: Columbia UP, 1990. Edición en español: L ógica del sentido. Trad. Miguel Morey y Víctor Molina. Barcelona: Paidós, 1994.

Fernández, Cristina B. "Escrito en la memoria (aproximaciones a la poesía de Jorge Luís Borges)." Q uaderni Ibero-A mericani 87-88 (2000): 56-72.

Freud, Sigmund. A G eneral Introduction to Psychoanalysis. Trans. John Riviere. New York: Simon and Schuster, 1969. 
. Civilization and Its D iscontents. Trans. James Strachey. New York: W. W. Norton, 1961.

Moraña, Mabel. "Borges y yo. Primera reflexión sobre 'El etnógrafo.' " $\mathrm{H}$ eterotropías: N arrativa de identidad y alteridad. Eds. Carlos Jaúregui y Juan Pablo Dabove. Pittsburgh: Pittsburgh UP, 2003. 263-86.

Regazzoni, Susanna. "El otro Borges." Rassegna iberística. 68 (2000): 41-50.

Reyes Pérez, José de los. A nálisis de El hacedor de Jorge L uís Borges. Caracas: La Casa de Bello, 1997.

Sarlo, Beatriz. Borges, un escritor en las orillas. Buenos Aires: Ariel, 1995.

Shellhorse, Adam J. "Lo otro en el mismo en incesante abismo: la poética borgeana de la reescritura en 'La dicha'-o lo dicho poético- en incesante diferencia derridiana." 12 de octubre de 2003 <http:/ / www.arches.uga.edu/ shellhor/ principal.htm> 1-10.

Simms, Ruth L. "Un vistazo a la poesía de Jorge Luís Borges." H ispania 35.4 (1952): 415-18.

Yates, D onald. "Borges: Philosopher? Poet? Revolutionary?" Jorge L uis Borges: Conversations. Ed. Richard Burgin. Jackson: UP of Mississippi, 1998. 192-98.

Zubizarreta, Armando F. " 'Borges and I,' A Narrative Sleight of Hand." Studies in 20 th Century L iterature 22.2 (1998): 371-81. 